\title{
MIGRAÇÃO, SITUAÇÕES DE POBREZA E CONDIÇÃO DOMICILIAR NA REDE DELOCALIDADES CENTRAIS DE UM BRASIL TRIPARTITE
}

\author{
Ralfo Matos \\ Ricardo Alexandrino Garcia ${ }^{*}$
}

\section{Resumo}

Os anos de 1980 e 1990 foram considerados, para vários analistas econômicosbrasileiros, como o período das décadas perdidas. As taxas de crescimento do PIB e a redução do nível de emprego na maior parte desse período faziam crer que o Brasil experimentava um momento crítico de estagnação e crise que atingia diretamente o Estado, a iniciativa privada e a população em idade de trabalhar. Neste artigo são discutidas seguintes questões: os migrantes dos últimos 20 anos, em busca de oportunidades de trabalho continuam procurando grandes cidades do sudeste, ou, não realizando esse objetivo a contento, se redistribuem por um conjunto maior de localidades que estariam oferecendo os empregos que tradicionalmente as grandes metrópoles eram as únicas que podiam oferecer?;como aferir de forma relativamente simples a condição de pobreza dessas populações? Pararesponder a essas indagações, processos socioeconômicos foram analisados com base em comparações focalizando os movimentos migratórios e suas relações com o crescimento populacional e o crescimento do emprego, bem como na exploração de variáveis que captam sinais materiais de pobreza nas instalações de que essas populações dispõem.

Palavras-chave: migração; pobreza; emprego; centralidade urbana

\footnotetext{
"Professor do Departamento de Geografia do IGC/UFMG, doutor em Demografia.

"Professor-pesquisador do IGC/UFMG, doutor em Demografia, bolsista do Programa PRODOC/CAPES.

Cadernos do Leste

Artigos Científicos

Belo Horizonte, Jan.-Dez. Vol.9, nº 2009
} 


\section{1- INTRODUÇÃO}

A ideia de que a migração contribui com o aumento da pobreza é antiga e recorrente. Desde o início do século XIX, com a forte expansão industrial na Inglaterra, discutia-se sobre a relação entre aumento da população - como resultado das ondas de migrantes prolíferos que afluíam às cidades - e aumento da pobreza. Aquela nova realidade social acabou se tornando uma questão de estado à época. Malthus, Ricardo e outros economistas clássicos discutiram, refletiram sobre os efeitos da Lei dos Pobres e teorizaram sobre a causalidade recíproca que percorre os fatores econômicos e as componentes da dinâmica demográfica. De toda forma, naquele momento de transformações revolucionárias era bastante evidente a condição de pobreza dos migrantes que chegavam às cidades. Se não vinham já empobrecidos em face das alterações fundiárias em suas áreas de origem, passavam a constituir legiões de novos pobres submetidos a um mundo ainda não regulamentado, onde longas jornadas de trabalho, ausência de direitos dos trabalhadores e super-exploração de crianças e mulheres era a regra.

Esse quadro sofreria mudanças na medida em que obras de infraestrutura e serviços públicos eram introduzidos nas cidades e novas regulamentações vieram arbitrar as relações envolvendo trabalhadores e empresas. Contudo, até fins do século XIX, o crescimento urbano e da população de Londres em particular impressionavam. Com a divulgação do Censo de 1881, e após reunir dados para mais de 20 países, E. G. Ravenstein publicou em Londres um trabalho intitulado "Leis da Migração". Eram sete as "leis" que explicariam os movimentos migratórios, sendo a força de atração das cidades muito destacada (conforme a lógica das distâncias, das etapas migratórias, dos diferenciais rural-urbanos e por sexo), embora dentre os vários motivos que produziam correntes migratórias nenhum deles comparava-se ao desejo “inerente à maioria dos homens de melhorar a sua situação material”. O autor afirmava que a propensão à migração entre os habitantes de áreas urbanas e rurais era diferente. Os naturais de cidades migravam menos que os naturais de áreas rurais e o incremento dos meios de comunicação e o desenvolvimento industrial e comercial incrementavam as migrações.(Ravenstein, 1980:286).

Contudo, já nas primeiras décadas do século XX, os movimentos internos depopulações em países europeus mais industrializados diminuíram e/ou se acomodaram. A grande onda das migrações internas de tipo campo-cidade fora uma realidade dos séculos XVIII e XIX e as migrações internacionais tomaram a dianteira na dinâmica demográfica desses países, ampliando a dramaticidade da Era das Catástrofes, como sugere Eric Hobsbawn. Em um outro mundo, no entanto, nos países capitalistas periféricos, aquele cenário de desolação dos primórdios da revolução industrial parecia se repetir, mas em umintervalo de tempo mais curto e em um quadro 
institucional mais precário e desigual, onde os processos de mudança econômica provocavam a desestabilização socioespacial e atingiam profundamente a vida de milhões de pessoas. Nesses países, os estudos sobre os fatores que explicavam a intensidade da imigração nas áreas urbanas lançaram luzes sobre as estruturas geradoras de iniquidades nas áreas rurais, as quais produziam contingentes de pobres que só tinham como alternativa a piora das condições de vida em minifúndios cercados de latifúndios ou a migração para as cidades. É verdade que, boa parte desses migrantes, após anos de experiência e adaptação cultural a rotinas de trabalho de tipo urbano-industrial, progrediu na vida, experimentando a chamada mobilidade social ascendente, mas muitos outros amargaram o insucesso na difícil jornada de sobrevivência nas grandes cidades ${ }^{1}$.

Nos anos 70, quando o Brasil vivia um processo de transição urbana acelerado, váriostextos seminais trataram desse tema, alguns aludindo a referenciais teóricos da Escola de Chicago, quando perguntavam se os migrantes se movimentavam em resposta à aspectos de seletividade na origem ou em face do imperativo da sobrevivência, e nesse caso os mais fortes se destacariam (Martine, 1980), outros ancorados no enfoque histórico-estrutural, a exemplo de Singer (1973), Testa (1970), Duhran (1973), observavam que as relações centroperiferiaeram essenciais para explicar os processos migratórios. A industrialização dos países centrais impacta fortemente a configuração demográfica, espacial e econômica das sociedades dependentes. A industrialização periférica acentuaria as disparidades regionais, incentivaria a migração ruralurbana, provocaria concentração populacional nas grandes cidades e produziria uma grande quantidade de excluídos da economia formal. Alguns pontos chaves da abordagem históricoestrutural podem ser resumidos assim: a migração deve ser analisada em suas inter-relações com outros processos globais e a análise deve ser referida historicamente, já que os fluxos alteram-se ao longo do processo de desenvolvimento. As causas devem ser rastreadas não apenas na origem e destino, mas analisadas tendo em conta os fluxos inter e intra regionais, sem perder de vista as estruturas econômicas, políticas, sociais e demográficas. Assim é relevante analisar as

\footnotetext{
${ }^{1}$ Em trabalho que se tornou clássico, o argentino Gino Germani considera a migração como um dos processos básicos da mobilidade social, eixo das mudanças do tradicional para o moderno. Esse processo se daria por meio de etapas, onde a desagregação da sociedade tradicional seria sucedida pela constituição de sociedade dualistas, com forte mobilização das massas, momento em que as migrações emergiam com intensidade. Sua teoria focalizava a migração campo-cidade, as estruturas agrárias deficientes, o alto crescimento demográfico rural, a questão da absorção dos migrantes rurais nas cidades, postulando que além dos fatores de expulsão e de atração, as condições socioculturais e subjetivas eram essenciais para o entendimento dos movimentos migratórios. Germani, ainda sugere diferenciar razões econômicas (salários, terras, desemprego, etc.), das razões domésticas, educacionais e entre outras. Oliveira e Stern (1980:27), entretanto, veem as migrações internas situadas "no processo mais geral de transformação socioeconômica de uma estrutura agrária em estrutura industrial”.
}

Cadernos do Leste 
determinações políticas e econômicas dadas pela estrutura de classes e como isto afeta os fluxos majoritários ${ }^{2}$.

De outra parte, a evidência empírica possibilitada pela divulgação dos dados doCenso de 1970 permitiu o surgimento de novos estudos, alguns, inclusive, contrariando o senso comum, ao concluírem que em vários lugares a migração afigurava-se como um processo gerador de benefícios para as áreas receptoras em oposição à teses conservadoras que diziam o oposto. Nesse sentido, um dos marcos nos estudos empíricos e indagaçõesteóricas devem ser tributados à Martine (1980) e Martine e Peliano (1978), quando suspeitavam que "a transformação no perfil ocupacional com o tempo de residência estaria refletindo nãosomente uma possível mobilidade, mas, de alguma forma, a evasão do mercado de trabalho degrupos migrantes menos qualificados... constatou-se ... significativa a observação de que amigração repetida aumenta rapidamente com a idade". Embora a hipótese clássica que tentava explicar esse processo fosse a da migração por etapas, o autor aventava outra hipótese relacionada à resignação de sucessivas ondas de migrantes ao que se oferecia nas cidades, tendo em vista os baixíssimos níveis de renda de expressivos contingentes da população migrante e não-migrante, independentemente da localidade (Martine e Peliano: 1978:173).

Os anos de 1980 e 1990 foram considerados, para vários analistas econômicosbrasileiros, como o período das décadas perdidas. De fato, as taxas de crescimento do PIB e a redução do nível de emprego na maior parte desse período faziam crer que o Brasil experimentava um momento crítico de estagnação e crise que atingia diretamente o Estado, a iniciativa privada e a população em idade de trabalhar. Assim, após muitos anos de estagnação e pífio crescimento econômico, associados a processos de reestruturação produtiva iniciados nos anos de 1990, podese levantar a questão migração x pobreza sobre outro prisma: os migrantes dos últimos 20 anos, em busca de oportunidades de trabalho continuam procurando grandes cidades do sudeste, ou, não realizando esse objetivo a contento, se redistribuem por um conjunto maior de localidades

\footnotetext{
${ }^{2}$ Singer (1976:122) recorria a Marx quando dizia que "a grande massa rural, confinada na economia desubsistência, passa a constituir para a economia capitalista industrial (...) um exército industrial de reserva",mas concordava que a melhoria das condições de vida do trabalhador urbano funcionava como fator de atraçãopara a população rural, posição semelhante à de Faria (1980), quando apontava a significativa mobilidade socialascendente no Brasil do período 1950-1980. Mas, para Singer, se era verdade que havia certa melhoria dascondições de vida nas cidades, e que a melhoria da infraestrutura de estradas e comunicações fazia aumentar asmigrações internas, os grandes fluxos de tipo campo-cidade se explicavam principalmente pelos chamadosfatores de expulsão. Aqui situava-se uma das principais contribuições teóricas de Singer no estudo dasmigrações internas. A desestabilização do mundo rural associava-se diretamente à desestruturação daseconomias de subsistência com a expansão do capitalismo. As estruturas fundiárias arcaicas e a crescentepressão populacional sobre a disponibilidade de áreas cultiváveis, em um momento em que o declínio damortalidade já produzia seus efeitos, só fazia agravar as iniquidades do quadro histórico-estrutural.
} 
que estariam oferecendo os empregos que tradicionalmente as grandes metrópoles eram as únicas que podiam oferecer?

Mais que isto, como aferir de forma relativamente simples a condição de pobrezadessas populações? Por meio de comparações focalizando renda per capita, nível de escolaridade, inserção no emprego formal? Ou por meio de variáveis que procurem captar sinais materiais de pobreza nas instalações materiais de que as pessoas dispõem?

De outra parte, convém mencionar um conhecido debate na literatura que se interpõediante de contextos em que a pobreza pode ser o resultado de processos econômicos geradores de riqueza. A pergunta, de resposta nem sempre evidente, é se as mudanças que causam reestruturações produtivas, na medida em que fazem surgir novos empregos e cria atividades capazes de produzir riqueza nova, também desestabilizam formas de produção e gêneros de vida anteriores, provocando com isso desocupação, exclusão social e novos focos de pobreza em várias regiões e localidades à margem dos efeitos multiplicadores dos investimentos econômicos.

\section{Um marco metodológico para a análise do caso brasileiro}

Várias das questões que circundam os temas migração e pobreza são demasiadocomplexas e não podem ser resolvidas por meio da abordagem que se propõe em sequência, mas podem ser mapeadas e analisadas tendo em conta algumas das dimensões sócio demográficasque permeiam esse debate.

Uma aproximação com parte das evidências inscritas nos problemas antes formuladosaponta a necessidade de explicitar as localidades que se destacaram em termos de crescimento demográfico (em boa parte alimentado por fluxos migratórios) e crescimento do emprego (em boa parte explicado pela expansão da atividade econômica). Emprego que, por sua vez, supostamente atrai migrantes e/ou favorece a expansão das famílias dos trabalhadores ocupados.

Diante disso, conviria focalizar as localidades que, em princípio, parecem convivercom dinamismo demográfico-econômico a fim de testar a hipótese de aumento da pobreza. De um total de 5.507 municípios brasileiros do Censo 2000 quantos são os que preenchem as duas condições, ou sejacrescimento expressivo do emprego e da população? Tomando como referência as taxas médias de crescimento do emprego no Brasil no período 1995 e 2000 e as taxas de crescimento da população estimada em 1995 e a do censo $2000^{3}$, obtêm-se duas medidas

\footnotetext{
${ }^{3}$ Essas taxas foram respectivamente, $1,75 \%$ ao ano no caso da população e 2,35\% no âmbito do empregoformal. Se o emprego formal se expandiu a taxa superior a do crescimento populacional é plausível esperar o incremento da migração? Cadernos do Leste 
paramétricas que serão utilizadas para discriminar os municípios que se destacaram efetivamente no período, os municípios notáveis. Os dados indicam que do total de 5.507 municípios cerca de $1 / 5$ deles, mais precisamente 1.102, constituem o conjunto dos municípios notáveis, os que exibiram crescimento demográfico e do emprego acima da média nacional no período $1995 / 2000$.

Os três mapas apresentados em sequência mostram que esse resultado é funçãoprincipalmente da expansão do emprego formal mais veloz que a expansão dos estoques populacionais. Houve mais municípios, particularmente fora das grandes metrópoles, a exibir taxas de crescimento dos trabalhadores com carteira assinada acima da média nacional do que municípios com ritmo de crescimento demográfico superior a média nacional entre 1995/2000.

\section{Mapa 1. Brasil: 1995-2000. Crescimento populacional nas frações da rede de localidade centrais.}

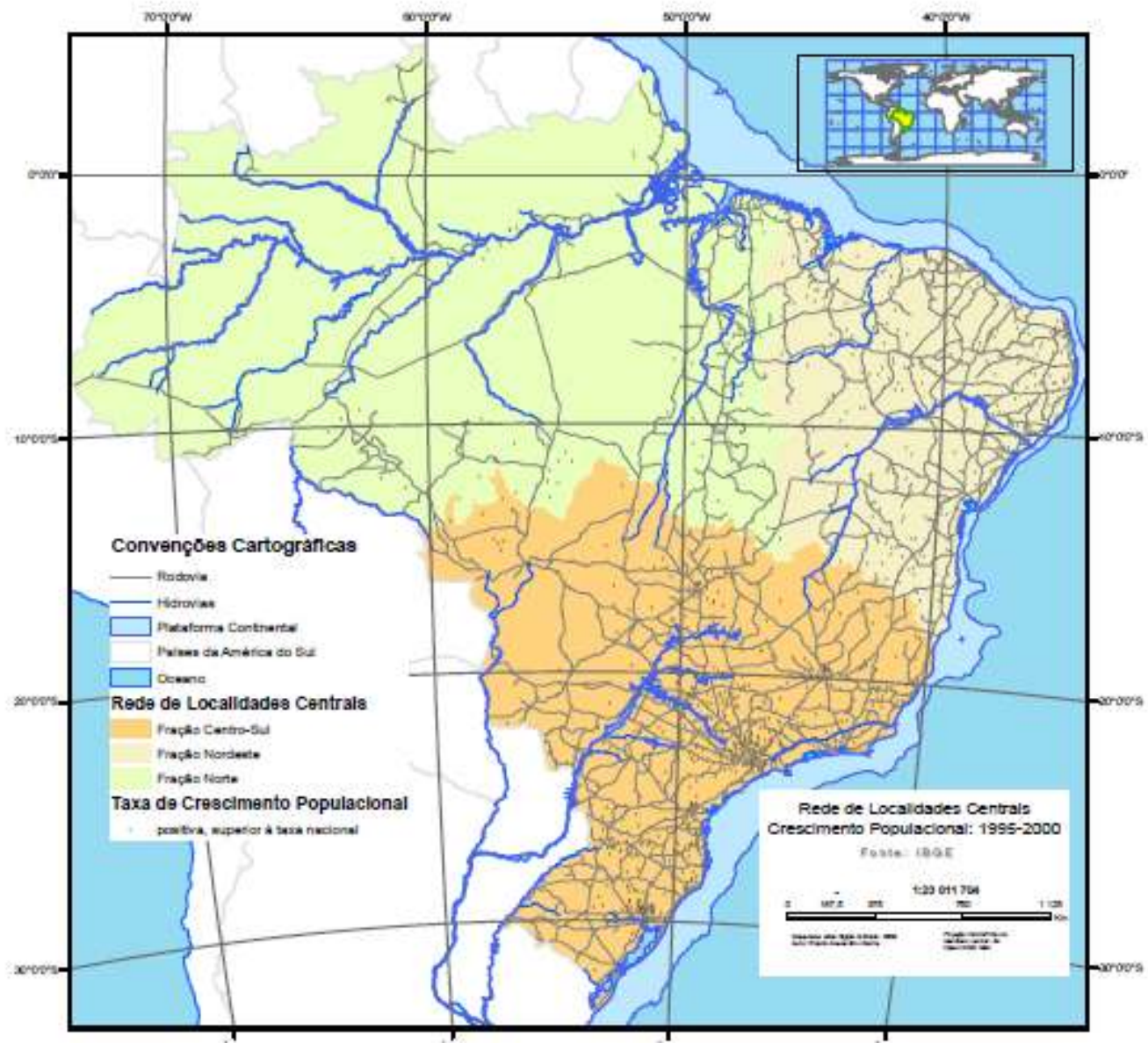

Fonte: IBGE, Censo Demográfico de 2000 e 1991; Laboratório de Estudos Territoriais - Leste/IGC. 
Mapa 2. Brasil: 1995-2000. Crescimento do emprego formal nas frações da rede de localidade centrais

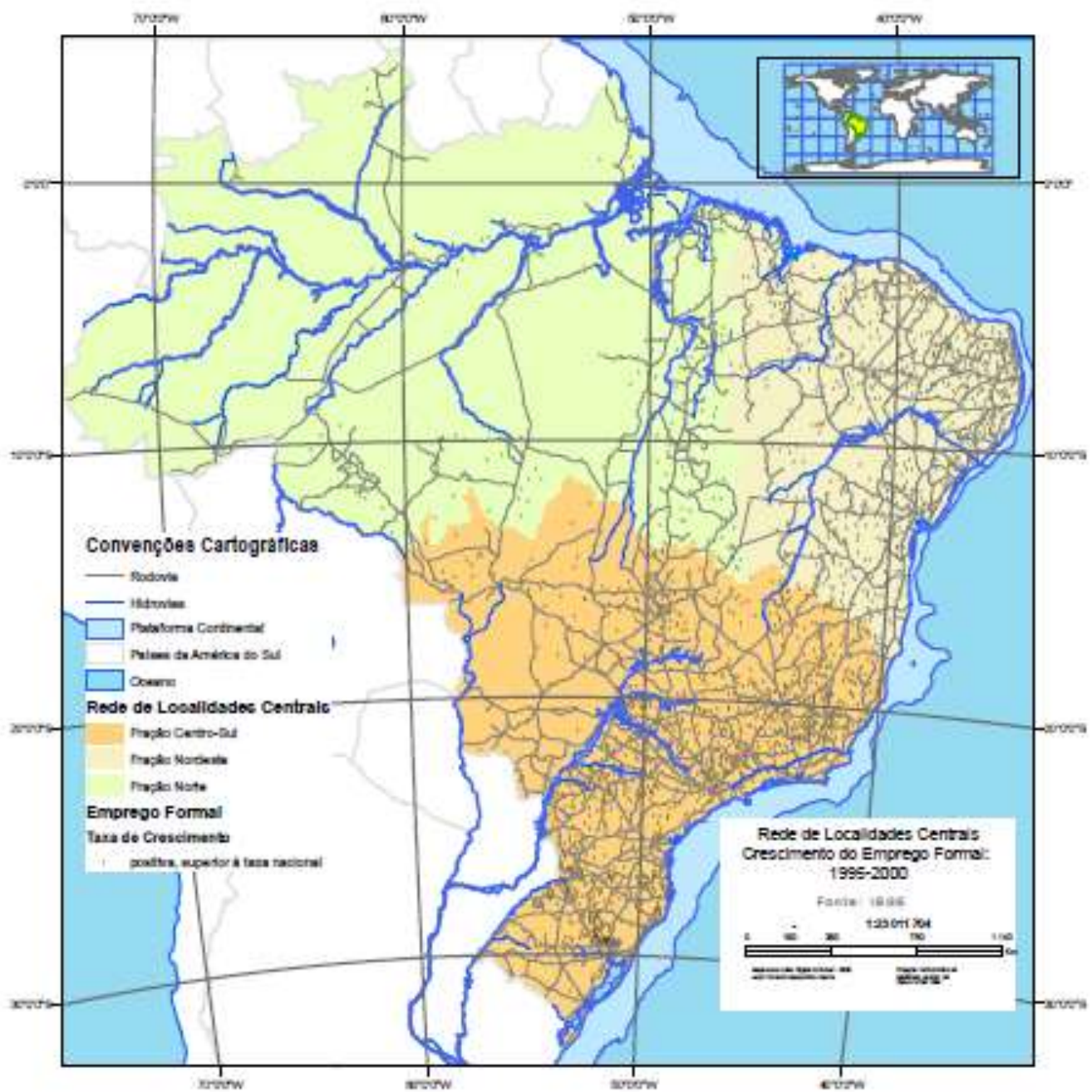

Fonte: Relação Anual de Informações Sociais - RAIS.

Por outro lado, se o país viveu nos últimos 50 anos um processo intenso deurbanização e redistribuição da população no espaço, importa considerar, de algum modo, esses aspectos na discussão sobre migração e pobreza. Uma forma usual de incorporar o incremento da urbanização é adotar recortes espaciais que possuam alguma sensibilidade para com essas mudanças. A identificação de localidades urbanas chaves e a classificação das localidades por tamanho são dois instrumentos bem conhecidos na literatura. Com a explicitação da rede de localidades centrais - em clara alusão à teoria do lugar central de Walter Christaller - pode-se verificar melhor as tendências dos movimentos populacionais mais relevantes e indicar onde estão os subespaços que vêm se notabilizando em termos de diferenciais econômicos e migratórios.

Cadernos do Leste 
Em Matos (2005) apresentou-se uma proposta relativamente simples para omapeamento da rede urbana brasileira atual. Os pontos da rede foram encontrados com base no peso demográfico das localidades urbanas e na presença de redes viárias interligando tais pontos. $\mathrm{O}$ município é a unidade mínima de observação, mas pode constituir "conglomerados" municipais no caso das Regiões Metropolitanas.

Os critérios, conforme primeira versão da rede urbana formulada em 1999,consideravam: i) municípios integrantes das Regiões Metropolitanas oficiais em 1991 (cada região metropolitana comparece, na rede urbana, como um nódulo de primeira ordem); ii) município com população urbana superior a 100 mil habitantes (pontos da rede que se equipara às chamadas Cidades Médias); iii) município cuja população urbana representasse mais de 3\% da população urbana do respectivo estado (pontos da rede de importância estadual); iv) município com população urbana superior a 3\% da população urbana do estado do Amazonas excluindo Manaus. Os dois últimos critérios procuram recobrir os contextos espaciais em que há municípios pouco populosos, mas de importância estratégica na rede urbana regional (como nos casos do Norte e Centro Oeste).

Adicionalmente, obteve-se uma regionalização tripartite semelhante à descrita porGeiger nos anos de 1960 aqui denominadas de fração Norte, fração Nordeste e fração Centro Sul, conforme mostram os mapas aqui apresentados. ${ }^{4}$

\section{Quantos são e onde estão os municípios líderes do crescimento demográfico e do emprego?}

Os dados da Tabela 1 ajudam a responder essa questão. A grande maioria dos 1.102municípios notáveis refere-se a municípios de menor tamanho. São 1.007 municípios, constantes da classe Demais Localidades, dos quais 947 tinham menos de 50 mil habitantes (entre eles, 710 com menos de 20 mil habitantes). Um conjunto tão expressivo de municípios de menor tamanho já indica a importância do processo de dispersão da população por um vasto espaço do interior brasileiro, não obstante a presença dos 95 municípios dinâmicos com mais de 50 mil habitantes constantes da Tabela 1.

\footnotetext{
${ }^{4}$ No ano 2000 de um total de 5507 municípios verificou-se que 77 deles correspondiam a municípios que formavam Centros Principais (os de primeira ordem, quase sempre regiões metropolitanas) no Centro Sul; 21 no Nordeste e apenas quatro na fração Norte. Os Centros Intermediários também mostraram-se mais numerosos na fração Centro Sul, 109, sucedidos pela fração Nordeste que detinha 34 municípios nessa condição enquanto a grande fração Norte apresentava outros 24. É evidente que, a imensa maioria das Demais Localidadescompunha-se de municípios relativamente pequenos, com menos de 20 mil habitantes (4.018), seguidos de 964 municípios com população entre 20 e 50 mil habitantes e outros 575 municípios com populações acima dos 50 mil.
}

Cadernos do Leste 
Tabela 1: Número de municípios notáveis segundo classe de tamanho e porte na Rede de Localidades Centrais em 2000

\begin{tabular}{|c|c|c|c|c|c|}
\hline \multirow{2}{*}{$\begin{array}{l}\text { Espaços da Rede de } \\
\text { Localidades Centrais }\end{array}$} & \multicolumn{5}{|c|}{ Municipios por classes de tamanho } \\
\hline & $\begin{array}{c}\text { Até 20 } \\
\text { Mil Hab. }\end{array}$ & $\begin{array}{c}\text { De } 20 \text { a } 50 \text { Mil } \\
\text { Hab. }\end{array}$ & $\begin{array}{c}\text { de } 50 \text { a } 100 \mathrm{Mil} \\
\text { Hab. }\end{array}$ & $\begin{array}{c}100 \text { Mil Hab ou } \\
\text { mais }\end{array}$ & Total \\
\hline \multicolumn{6}{|l|}{ Centros Principais } \\
\hline Centro-Sul & & & 11 & 17 & 28 \\
\hline Nordeste & & & 5 & 2 & 7 \\
\hline Norte & & & 1 & 1 & 2 \\
\hline \multicolumn{6}{|l|}{ Centros Intermediários } \\
\hline Centro-Sul & & & 6 & 26 & 32 \\
\hline Nordeste & & & 2 & 9 & 11 \\
\hline Norte & & & 9 & 6 & 15 \\
\hline \multicolumn{6}{|l|}{ Demais Localidades } \\
\hline Centro-Sul & 361 & 102 & 33 & 4 & 500 \\
\hline Nordeste & 196 & 68 & 18 & 1 & 283 \\
\hline Norte & 153 & 62 & 8 & 1 & 224 \\
\hline Brasil & 710 & 232 & 93 & 67 & 1.102 \\
\hline
\end{tabular}

Não há dúvidas de que a participação do Centro Sul é muito expressiva porquesozinho responde por cerca de 50\% (560 municípios) dos 1.102 municípios notáveis. Contudo, não convém minimizar as participações das frações Nordeste e Norte, onde se localizam a outra metade de municípios. No Centro Sul, onde é intensa a urbanização, comparecem municípios de grande população, afinal são 28 e 32 municípios que se destacaram entre os Centros Principais e Centros Intermediários mais dinâmicos do período. Esses números são superiores às participações somadas do Nordeste e Norte, embora os 15 municípios do Norte e os 11 do Nordeste do rol dos Centros Intermediários mereçam destaque. Resta avaliar o tamanho dos estoques populacionais referidos à essas classificações por tamanho e hierarquia.

Os números da Tabela 2 indicam que 20,6\% dos 169.799.170 relativos à populaçãototal do país no ano 2000 residiam nos municípios notáveis, número que corresponde aos mesmos 20\% de municípios enumerados na Tabela 1. 
Tabela 2: População residente nos municípios notáveis segundo classe de tamanho e porte na Rede de Localidades Centrais em 2000

\begin{tabular}{|c|c|c|c|c|c|}
\hline \multirow{2}{*}{$\begin{array}{l}\text { Espaços da Rede de } \\
\text { Localidades Centrais }\end{array}$} & \multicolumn{5}{|c|}{ Municipios por classes de tamanho } \\
\hline & $\begin{array}{c}\text { Até 20 } \\
\text { Mil Hab. }\end{array}$ & $\begin{array}{c}\text { De } 20 \text { a } 50 \text { Mil } \\
\text { Hab. }\end{array}$ & $\begin{array}{c}\text { De } 50 \text { a } 100 \text { Mil } \\
\text { Hab. }\end{array}$ & $\begin{array}{c}100 \text { Mil Hab ou } \\
\text { mais }\end{array}$ & Total \\
\hline \multicolumn{6}{|l|}{ Centros Principais } \\
\hline Centro-Sul & & & 799.597 & 5.195 .501 & 5.995 .098 \\
\hline Nordeste & & & 376.643 & 242.245 & 618.888 \\
\hline Norte & & & 74.429 & 393.569 & 467.998 \\
\hline Subtotal & & & 1.250 .669 & 5.831 .315 & 7.081 .984 \\
\hline \multicolumn{6}{|l|}{ Centros Intermediários } \\
\hline Centro-Sul & & & 451.309 & 5.122 .885 & 5.574 .194 \\
\hline Nordeste & & & 141.460 & 1.969 .255 & 2.110 .715 \\
\hline Norte & & & 644.148 & 1.089 .381 & 1.733 .529 \\
\hline Subtotal & & & 1.236 .917 & 8.181 .521 & 9.418 .438 \\
\hline \multicolumn{6}{|l|}{ Demais Localidades } \\
\hline Centro-Sul & 3.298 .913 & 3.098 .053 & 2.322 .901 & 425.367 & 9.145 .234 \\
\hline Nordeste & 1.962 .376 & 2.069 .521 & 1.215 .048 & 107.486 & 5.354 .431 \\
\hline Norte & 1.423 .937 & 1.835 .278 & 520.177 & 119.152 & 3.898 .544 \\
\hline Subtotal & 6.685 .226 & 7.002 .852 & 4.058 .126 & 652.005 & 18.398 .209 \\
\hline Brasil & 6.685 .226 & 7.002 .852 & 6.545 .712 & 14.664 .841 & 34.898 .631 \\
\hline
\end{tabular}

Cerca de 34,9 milhões de pessoas se distribuíam da seguinte forma: 20,3\% residiamnos Centros Principais, 27,0\% nos Centros Intermediários e 52,7\% nas Demais Localidades. Essa participação relativa tão grande da população dos 1.007 municípios dinâmicos de pequeno porte $(52,7 \%)$ não causa estranheza, porque envolve bases de comparação estatística de pequeno tamanho de um censo a outro, suscetíveis de alterações muito rápidas de suas taxas de crescimento, em visível contraste com a situação de municípios de grande tamanho. Entretanto, no caso dos Centros Intermediários o mesmo raciocínio já não se aplica em face do tamanho bem mais expressivo dos municípios. De toda sorte, na soma dos Centros Intermediários e das Demais Localidades, há um estoque populacional significativo (27.8 milhões de pessoas) que deve estar se beneficiando da expansão do emprego formal acima da média nacional.

Os dados da RAIS $^{5}$ indicam que havia 4.672 .661 pessoas empregadas nos 1.102 municípios aqui trabalhados e isso equivalia a cerca de 17,8\% dos empregos formais registrados no país no ano 2000. A grande maioria desses empregos estava no Centro Sul, sobretudo, nos Centros Principais e nas Demais Localidades. Diante dos dados de população e emprego, uma primeira conclusão se faz evidente: a concentração do emprego formal no Centro Sul se mostrava bem maior que a concentração da população na mesma fração.

\footnotetext{
${ }^{5}$ A base de dados da Relação Anual de Informações Sociais - RAIS é constituída e atualizada a partir deinformações sobre características dos empregados que empresas e empregadores são obrigados a informar anualmente ao Ministério do Trabalho. A RAIS é uma espécie de um censo administrativo sobre o mercado de trabalho, mas parcial porque exclui os trabalhadores autônomos, empresários sem vínculo empregatício formal e todos os demais trabalhadores que não possuem registro em carteira de trabalho. Contudo, é uma valiosa fonte de dados, por ser anual, de fácil desagregação espacial, o que permite superar as limitações associadas à periodicidade dos censos.
}

Cadernos do Leste 
Tabela 3: Total de pessoas empregadas nos municípios notáveis segundo classe de tamanho e porte naRede de Localidades Centrais em 2000

\begin{tabular}{|c|c|c|c|c|c|}
\hline \multirow{2}{*}{$\begin{array}{l}\text { Espaços da Rede de } \\
\text { Localidades Centrais }\end{array}$} & \multicolumn{5}{|c|}{ Municipios por classes de tamanho } \\
\hline & $\begin{array}{c}\text { Até } 20 \\
\text { Mil Hab. }\end{array}$ & $\begin{array}{c}\text { De } 20 \text { a } 50 \text { Mil } \\
\text { Hab. }\end{array}$ & $\begin{array}{c}\text { De } 50 \text { a } 100 \text { Mil } \\
\text { Hab. }\end{array}$ & $\begin{array}{l}100 \text { Mil Hab ou } \\
\text { mais }\end{array}$ & Total \\
\hline \multicolumn{6}{|l|}{ Centros Principais } \\
\hline Centro-Sul & & & 192.359 & 1.203 .900 & 1.396 .259 \\
\hline Nordeste & & & 49.446 & 50.646 & 100.092 \\
\hline Norte & & & 2.355 & 26.570 & 28.925 \\
\hline \multicolumn{6}{|l|}{ Centros Intermediários } \\
\hline Centro-Sul & & & 29.430 & 862.786 & 892.216 \\
\hline Nordeste & & & 9.900 & 192.424 & 202.324 \\
\hline Norte & & & 44.095 & 178.478 & 222.573 \\
\hline \multicolumn{6}{|l|}{ Demais Localidades } \\
\hline Centro-Sul & 473.253 & 477.554 & 337.670 & 70.124 & 1.358 .601 \\
\hline Nordeste & 105.604 & 116.299 & 84.366 & 10.200 & 316.469 \\
\hline Norte & 49.989 & 63.522 & 39.129 & 2.562 & 155.202 \\
\hline Brasil & 628.846 & 657.375 & 788.750 & 2.597 .690 & 4.672 .661 \\
\hline
\end{tabular}

De fato, ao que tudo indica o emprego formal experimenta uma desconcentraçãogeográfica mais restrita às áreas de influência dos principais centros urbanos do país, particularmente no Sudeste e no estado de São Paulo. A desconcentração demográfica, por outro lado, é bem mais abrangente espacialmente. Os dados em sequência não deixam dúvidas. $O$ grosso do emprego dos Centros Principais, dos Centros Intermediários e das Demais Localidades está na fração Centro Sul, algo em torno de $79 \%$ se somadas as três participações, enquanto a participação da população residente não ultrapassa os 60\% (Tabela 4). Com isso, pode-se deduzir que parte expressiva do crescimento populacional verificado nos Centros Intermediários e Demais Localidades das frações Norte e Nordeste não se ampara no crescimento do emprego formal.

Tabela 4: Participação do emprego formal e da população residente nos municípios notáveis da Rede de Localidades Centrais em 2000

\begin{tabular}{lrr}
\hline Espaços da Rede de & \multicolumn{2}{c}{ Percentuais Relativos } \\
\cline { 2 - 3 } Localidades Centrais & \multicolumn{1}{c}{ Emprego } & Populaçào \\
\hline Centros Principais & 29,88 & 17,18 \\
Centro-Sul & 2,14 & 1,77 \\
Nordeste & 0,62 & 1,34 \\
Norte & 19,09 & 15,97 \\
Centros Intermediários & 4,33 & 6,05 \\
Centro-Sul & 4,76 & 4,97 \\
Nordeste & & \\
Norte & 29,08 & 26,21 \\
Demais Localidades & 6,77 & 15,34 \\
Centro-Sul & 3,32 & 11,17 \\
Nordeste & $\mathbf{4 . 6 7 2 . 6 6 1}$ & 34.898 .631 \\
Norte &
\end{tabular}

Fonte: IBGE, Censo Demográfico de 2000 e Relação Anual de Informações Sociais - RAIS; Laboratóno de Estudos Ternitoriais - Leste/IGC. 
É evidente que grande parte dos migrantes se movem no espaço em busca deoportunidades econômicas diversas e o emprego formal é apenas uma delas, talvez a menos importante, se levamos em conta as altas proporções de trabalhadores ocupados no setorinformal e as conclusões acima sublinhadas. Talvez por tudo isso, seja sempre necessário verificar quais são os municípios que mais atraem migrantes, já que essa atração deve se apoiar em algum tipo de oportunidade de trabalho. No caso dos municípios notáveis que, por definição, são mais dinâmicos, esse tipo de indagação deve abrir níveis desejáveis de detalhamento em temos socioespaciais.

\section{Os municípios notáveis atraem mais migrantes?}

Examinando os saldos migratórios positivos do período 1995-2000 constata-se que a migração foi importante nos 1.102 municípios dinâmicos aqui selecionados. Isso é necessário ressaltar porque no Brasil, embora seja muito forte o movimento das populações entre os mais diferentes espaços, prevalece um quadro de perdas na migração intermunicipal. A quantidade de municípios com taxas migratórias negativas é muito significativa. Mesmo entre os municípios notáveis, há exemplos de taxas negativas, como no caso das Demais Localidades da fração Norte.

Contudo, o que de mais relevante se constata pelos dados da Tabela 5 resume-se a dois tipos de evidências. A primeira envolve os chamados Centros Principais, mas, sobretudo os municípios de menos de 100 mil habitantes conurbadoscom áreas metropolitanas. Nesse caso, não obstante a presença de taxas relativamente modestas à medida que aumenta o tamanho dos municípios, entre os municípios da classe 50 a 100 mil habitantes, verificam-se, em todas as frações, Taxas Líquidas de Migração muito altas. Tudo indica que boa parte desses municípios, ao localizarem-se em periferias metropolitanas, devem conviver com incremento populacional provavelmente associado a situações de pobreza e subemprego.

A segunda conclusão diz respeito a forte presença de municípios que abrigam cidades médias com taxas de migração relativamente altas, particularmente na classe de tamanho de 50 a 100 mil habitantes na fração Centro Sul (7,94\%) e na classe de tamanho 100 mil ou mais da fração Norte $(2,95 \%)$.

Cadernos do Leste

Artigos Cientificos

Belo Horizonte, Jan.-Dez. Vol.9, n 9009 
Tabela 5

Taxa líquida de migração dos municípios notáveis segundo classe de tamanho e porte na

Rede de Localidades Centrais em 2000

\begin{tabular}{|c|c|c|c|c|c|}
\hline \multirow{2}{*}{$\begin{array}{l}\text { Espaços da Rede de } \\
\text { Localidades Centrais }\end{array}$} & \multicolumn{5}{|c|}{ Taxa líquida de migração dos municipios notáveis entre $1995 / 2000$} \\
\hline & $\begin{array}{c}\text { Até 20 } \\
\text { Mil Hab. }\end{array}$ & $\begin{array}{c}\text { De } 20 \text { a } 50 \text { Mil } \\
\text { Hab. }\end{array}$ & $\begin{array}{c}\text { De } 50 \text { a } 100 \text { Mil } \\
\text { Hab. }\end{array}$ & $\begin{array}{c}100 \text { Mil Hab ou } \\
\text { mais }\end{array}$ & Total \\
\hline \multicolumn{6}{|l|}{ Centros Principais } \\
\hline Centro-Sul & & & 7,49 & 0,86 & 1,11 \\
\hline Nordeste & & & 3,59 & 0,33 & 0,57 \\
\hline Norte & & & 20,02 & 2,11 & 2,47 \\
\hline \multicolumn{6}{|l|}{ Centros Intermediários } \\
\hline Centro-Sul & & & 7,94 & 1,64 & 1,84 \\
\hline Nordeste & & & 1,01 & 0,82 & 0.83 \\
\hline Norte & & & 0,71 & 2,95 & 2,30 \\
\hline \multicolumn{6}{|l|}{ Demais Localidades } \\
\hline Centro-Sul & 1,41 & 1,77 & 1,52 & 2,43 & 1,58 \\
\hline Nordeste & 0,22 & 0,10 & 0,68 & 0,09 & 0,25 \\
\hline Norte & 3,89 & 2,20 & -042 & $-3,28$ & 2,38 \\
\hline Brasil & 1,20 & 1,13 & 1,97 & 1,13 & 1,25 \\
\hline
\end{tabular}

Algumas conclusões até aqui verificadas podem ser sumariadas da seguinte forma. $\mathrm{O}$ crescimento populacional dos municípios notáveis localizados fora do Centro Sul não se apoia no crescimento do emprego formal, tal como ocorre nos municípios do Centro Sul. Adicionalmente, convém frisar que uma parte muito importante do crescimento da população do Centro Sul é resultante da forte presença de migrantes nas periferias metropolitanas e do recente dinamismo dos centros intermediários. Há portanto uma dúvida sobre até que ponto os municípios notáveis empregam de fato, mais ou menos, migrantes.

Embora não seja objetivo desse artigo aprofundar a discussão sobre migração e emprego é bem provável que, mesmo nos municípios notáveis, onde o crescimento do emprego formal manteve-se acima da média nacional, predomina o emprego informal. A verificação dessa questão pode trazer mais evidências sobre a redistribuição da pobreza e se a migração pode ter contribuído para a resultante encontrada.

Como esse estudo utiliza-se de duas bases de dados distintas, Censo e RAIS, e não é possível fazer comparações diretas entre as duas fontes, algumas deduções só podem ser feitas sobre a real participação dos imigrantes na oferta de empregos formais nos municípiosnotáveis por meio dos resultados censitários de 2000.

Uma rápida confrontação dos dados de migração (de data fixa) do Censo de 2000 nos diz que a maior parte dos imigrantes brasileiros não possuíam carteira assinada à data do recenseamento. Apenas $17,02 \%$ dos que residiam nos municípios brasileiros no ano 2000 possuíam carteira assinada enquanto nos municípios notáveis esse percentual era ainda menor 16,84\%. Contudo, a distribuição por classe de tamanho dos percentuais indica outra tendência. Se é evidente que os imigrantes parecem ter mais oportunidades de inserção no emprego formal nos municípios maiores, como mostram os percentuais de $21,1 \%$ e $20,1 \%$ da Tabela 6 , no rol dos municípios notáveis as chances são mais bem distribuídas, pois nas classes de menor tamanho as 
proporções são mais expressivas que no conjunto maior dos municípios brasileiros. Cerca de $14,3 \%$ e $12,7 \%$ dos imigrantes residentes nos municípios notáveis nas classes de tamanho 20 a 50 mil e até 20 mil habitantes, respectivamente, possuíam empregos com carteira assinada no ano 2000.

Tabela 6

Percentuais de imigrantes (de Data Fixa) empregados com carteira assinada segundo subespaços de residência no ano 2000 , por classes de tamanho dos municípios. Local de residência dos imigrantes Ate 20 de 20 a 50 de $100 \mathrm{Mil}$ Hab ou Total

\begin{tabular}{lrrrrr} 
& Mil Hab. & Mil Hab. & Hab. & \multicolumn{1}{l}{ mais } \\
\hline Municipios brasileiros & 10,90 & 12,85 & 16,65 & 21,10 & 17,02
\end{tabular}

Antes de proceder a análise da população imigrante empregada em $2000^{6}$ nas frações e subespaços da Rede de Localidades Centrais (RLC) pode se fazer algumas comparações iniciais. Uma comparação pertinente refere-se ao universo maior das 23,93 milhões de pessoas ocupadas com carteira assinada registrados no Censo 20008. Desse total 40,1\% residiam nos Centros Principais, 26,2\% nos Centros Intermediários e 40,6\% nas Demais Localidades, explicitando a concentração do emprego nos grandes centros urbanos. Se essasproporções se referirem aos 1.102 municípios notáveis os resultados são bem diferentes e expressam uma distribuição mais desconcentrada, já que 27,3\% dos empregados residiam nosCentros Principais, 31,3\% nos Centros Intermediários e 41,4\% nas Demais Localidades. Aquios números favoreceram claramente os Centros Intermediários, provavelmente em razão daforte redução da proporção relativa aos grandes centros.

Se o foco muda e expõe exclusivamente a população imigrante, a distribuição passa a ser a seguinte: $36,8 \%$ do total dos imigrantes com carteira assinada residiam nos CentrosPrincipais, 27,3\% nos Centros Intermediários e 36,0\% nas Demais Localidades. Tais números revelam uma concentração do emprego nos grandes centros inferior à distribuição dos 23,9 milhões de empregados em 2000 como mostrado. Se o rol dos municípios se referiraos notáveis o emprego torna-se ainda mais desconcentrado espacialmente, uma vez que só27,6\% dos imigrantes residiam em municípios que integravam Centros Principais, contra 29,3\% que residiam nos Centros Intermediários e 43,0\% que residiam nas Demais Localidades.

\footnotetext{
${ }^{6}$ Esse número não coincide com 26,3 milhões dos levantamentos da RAIS por uma série de razões mas nos dizem claramente que há forte correspondência entre eles. Para maiores detalhes, ver Nunes e Matos (2004) onde as divergências entre os valores do Censo e da Rais são analisadas.
}

Cadernos do Leste

Artigos Cientificos

Belo Horizonte, Jan.-Dez. Vol.9, nº 2009 
O quadro abaixo resume as observações supracitadas em relação a distribuição e concentração de pessoas com carteira assinada nos Centros Principais (CP), Centros Intermediários (CI) e Demais Localidades (DL).

Em síntese, reapresentando a pergunta se os municípios notáveis empregavam relativamente mais migrantes, a primeira resposta é não. Fora dos municípios notáveis encontram-se até mais imigrantes ocupados no mercado de trabalho formal, embora os números percentuais sejam próximos: 17,02\% estavam empregados nos municípiosbrasileiros contra 16,84\% nos municípios notáveis. Contudo, nos municípios notáveis o emprego se revelou mais bem distribuído pelas classes de tamanho aqui analisadas.

Quadro 1
Discriminação dos empregados com carteira assinada Centros Principais (CP), Centros
Intermediários (CI) e Demais Localidades (DL) da Rede de Localidades Centrais
\begin{tabular}{|lrrr|}
\hline Discriminação dos empregados com carteira assinada & CP & Cl & DL \\
\hline Empregados em 2000 & $40,1 \%$ & $26,2 \%$ & $40,6 \%$ \\
Empregados nos municípios notáveis & $31,3 \%$ & $31,3 \%$ & $41,4 \%$ \\
Imigrantes empregados em 2000 & $36,8 \%$ & $27,3 \%$ & $36,0 \%$ \\
Imigrantes empregados nos municípios notáveis & $27,6 \%$ & $29,3 \%$ & $43,0 \%$ \\
\hline
\end{tabular}
Fonte: IBGE, Censo Demográfico de 2000; Laboratório de Estudos Territoriais - Leste/IGC.

\section{Como se distribuía o emprego formal entre as frações da RLC?}

Resgatando as análises calcadas nas três grandes regiões da Rede de Localidades Centrais (RLC) pode-se concluir sobre quais regiões vêm empregando mais imigrantes. Os dados organizados em sequência permitem responder a indagação acima, ao reunir dois conjuntos, os dos municípios brasileiros e o dos municípios notáveis segundo o tamanho e porte dos espaços da RLC. Em todos os casos a oferta de empregos comcarteira assinada é maior no Centro Sul, mas enquanto no conjunto geral de municípios brasileiros o Nordeste surge como a segunda região empregadora, entre os municípios notáveis é o Norte que detém esse posto.

Atentando para a participação dos municípios notáveis na oferta de empregos formais pode-se assinalar algumas conclusões que conferem alguma especificidade a eles em relação ao conjunto maior de municípios brasileiros. As principais delas, à luz da Tabela 7, podem assim ser sumarizadas: a) Nos maiores municípios brasileiros há níveis elevados de concentração de imigrantes empregados (proporções superiores aos 91\%) em todas as três regiões, mas entre os municípios notáveis essa tendência se arrefece, mesmo no Centro Sul (82,5\%); b) Nos Centros Intermediários repete-se a mesma tendência. Entre os municípios notáveis, os de tamanho menor, como os da classe 50 a 100 mil habitantes, só têm mais expressão relativa na região Norte, onde 32,7\% dos ocupados lá residiam; c) nas Demais Localidades inverte-se a tendência 
observada acima ${ }^{7}$. As proporções de imigrantes empregados nos municípios notáveis na menor classe de tamanho é inferior às proporções relativas ao Brasil (32,4\%, 27,3\% e 35,8\%), não obstante o fato de ela representar 15,1\% dos773.370 mil imigrantes. Essa evidência também reafirma que as participações relativas dos imigrantes empregados nos municípios notáveis mostram-se mais bem distribuídas que no conjunto de municípios brasileiros, provavelmente em razão da menor presença de grandes municípios em periferias metropolitana a oferecer emprego formal, como ocorre no conjuntomaior de municípios brasileiros $(61,0 \%)$.

Tabela 7

Imigrantes empregados com carteira assinada em 2000 nos municipios brasileiros e nos municípios notáveis segundo classes de tamanho e porte dos municípios da Rede de

\begin{tabular}{|c|c|c|c|c|c|c|c|c|c|c|}
\hline \multirow{3}{*}{$\begin{array}{l}\text { Espacos da Rede de } \\
\text { Localidades Centrais } \\
\end{array}$} & \multicolumn{10}{|c|}{ Localidades Centrais $^{10}$} \\
\hline & \multicolumn{2}{|c|}{\begin{tabular}{l|l}
\multicolumn{2}{c}{ Até 20 mil hab. } \\
Brasil & Notativeis \\
\end{tabular}} & \multicolumn{2}{|c|}{\begin{tabular}{c|c}
\multicolumn{2}{c}{20 a 50 mil bab. } \\
Brasil & Notáreis
\end{tabular}} & \multicolumn{2}{|c|}{\begin{tabular}{|l|l|}
\multicolumn{2}{|c|}{50 a 100 mil hab. } \\
Brasil & Notáiveis \\
\end{tabular}} & \multirow{2}{*}{\multicolumn{2}{|c|}{\begin{tabular}{|l|l|}
\multicolumn{2}{|c|}{100 mil e mais } \\
Brasil & Notativeis \\
\end{tabular}}} & \multicolumn{2}{|c|}{ Totais $100 \%$} \\
\hline & & & & & & & & & & \\
\hline & & & & & 7,5 & 17,5 & & & & \\
\hline & & & & & 4.2 & 13,5 & 95,8 & 86,5 & 33.899 & 10.695 \\
\hline Centro & & & & & & & & & & \\
\hline $\mathrm{Co}$ & & & & & $\begin{array}{l}3.9 \\
4.5\end{array}$ & 6.0 & 95.5 & 94,0 & $\begin{array}{l}557.264 \\
104.551\end{array}$ & $\begin{array}{r}1655,044 \\
29.631\end{array}$ \\
\hline $\begin{array}{l}\text { Nort } \\
\text { Demai }\end{array}$ & & & & & 28.5 & 32,7 & 71,5 & 67,3 & 48.582 & 32.199 \\
\hline Demai & & & & & & & & & & \\
\hline & & & & & & $\begin{array}{l}20,3 \\
33,8\end{array}$ & & 盛 & & \\
\hline & & 35. & & 41.8 & & 20,3 & 0.3 & 2,1 & 67.465 & \\
\hline Brasil & 13,3 & 15,1 & 12,4 & 15,8 & 13,3 & 19,1 & 61,0 & 49,9 & 2606.676 & 773.370 \\
\hline
\end{tabular}

\section{Condições Domiciliares}

O emprego formal é um indicador de inserção do trabalhador no mercado de trabalho que sinaliza para situações de não-pobreza, sobretudo se os novos postos de trabalho forem relativamente estáveis, pagarem salários não escorchantes e se os números relativos ao trabalho informal, geralmente precarizado, não forem muito altos. Uma outra evidência de pobreza pode ser analisada por meio das condições de moradia dos ocupados. Embora não seja uma regra absoluta, pode-se afirmar, com base nas classificações do IBGE, que uma expansão dos domicílios particulares improvisados é sinal de expansão da pobreza.

Uma observação inicial relativa aos domicílios permanentes aponta algo esperado, os municípios mais dinâmicos, os notáveis, experimentam uma expansão dos domicílios permanentes no período 1991/2000 bem superior a expansão do conjunto maior, quase 5\% aoano contra os 2,9\% relativos ao total geral (Tabela 8). Algumas das maiores taxas de crescimento referem-se a municípios do Centro Sul (onde os números absolutos são sempremaiores), seja os que compõem os Centros Principais ( $6 \%$ a.a.), ou os Centros

\footnotetext{
${ }^{7}$ A distribuição da população nas categorias espaciais aqui expostas mantém aquilo que é óbvio: nos Centros Principais há mais gente concentrada nos maiores municípios; nas Demais Localidades há maior volume de população concentrada nos municípios menores (em face do seu número).
}

Cadernos do Leste 
Intermediários(4,51\% a.a.) e Demais Localidades (4,89\% a.a.). Outros incrementos dignos de nota dizem respeito ao Norte do país, mas nesse caso os números absolutos são bem mais modestos. Detoda forma, mesmo no Nordeste os dados indicam claramente que os domicílios permanentesnos municípios notáveis crescem a taxas bem superiores que as taxas de crescimento demográfico. Um antigo e recorrente desejo dos brasileiros de possuir sua casa própria, frequentemente mediante a ajuda de parentes amigos sob a forma de auto-construção e mutirão, continua, ao que tudo indica, forte e difuso espacialmente. São, em sua maioria, habitações relativamente precárias, mas ainda assim permanentes, conforme definição do

$\mathrm{IBGE}^{8}$. Os domicílios ditos improvisados são, em sua grande maioria, bem mais precários doponto de vista material e psicossocial do que os domicílios permanentes.

Tabela 9

Domicílios improvisados no total geral dos municípios brasileiros em 2000 e entre os

\begin{tabular}{|c|c|c|c|c|c|c|}
\hline \multirow{3}{*}{$\begin{array}{c}\text { Espaços da Rede de Localidades } \\
\text { Centrais }\end{array}$} & \multicolumn{6}{|c|}{ Domicilios Improvisados } \\
\hline & \multicolumn{3}{|c|}{ Total Geral } & \multicolumn{3}{|c|}{ Notáveis } \\
\hline & 1991 & 2000 & Taxa & 1991 & 2000 & Taxa \\
\hline \multicolumn{7}{|l|}{ Centros Principais } \\
\hline Centro-Sul & 24.155 & 42.989 & 6,61 & 3.912 & 8.672 & 9,25 \\
\hline Nordeste & 5.663 & 9.206 & 5,55 & 374 & 946 & 10,9 \\
\hline Norte & 4.997 & 2.600 & $-7,00$ & 41 & 427 & 29,7 \\
\hline \multicolumn{7}{|l|}{ Centros Intermediários } \\
\hline Centro-Sul & 13.948 & 23.041 & 5,74 & 3.288 & 6.951 & 8,67 \\
\hline Nordeste & 5.345 & 11.719 & 9,11 & 1.405 & 2.565 & 6,92 \\
\hline Norte & 9.499 & 5.529 & $-5,84$ & 2.257 & 4.010 & 6,59 \\
\hline \multicolumn{7}{|l|}{ Demais Localidades } \\
\hline Centro-Sul & 34.075 & 70.661 & 8,44 & 7.815 & 19.216 & 10,51 \\
\hline Nordeste & 17.114 & 47.665 & 12,05 & 2.946 & 11.534 & 16,38 \\
\hline Norte & 22.302 & 33.321 & 4,56 & 8.221 & 18.092 & 9,16 \\
\hline Brasil & 137.098 & 246.731 & 6,75 & 30.259 & 72.413 & 10,18 \\
\hline
\end{tabular}

Fonte: IBGE, Laboratónio de Estudos Territoriais (Leste/IGC-UFMG).

\section{Considerações finais}

$\mathrm{Na}$ explicitação das localidades que se destacaram em termos de crescimentodemográfico, que em boa parte é alimentado por fluxos migratórios, e crescimento do emprego, que em boa

\footnotetext{
${ }^{8}$ Para o IBGE, domicílio é o "local estruturalmente separado e independente que se destina a servir dehabitação a uma ou mais pessoas, ou que esteja sendo utilizado como tal. A separação caracteriza-se quando o local de moradia é limitado por paredes, muros ou cercas, coberto por um teto, permitindo a uma ou mais pessoas, que nele habitam, isolar-se das demais, com a finalidade de dormir, preparar e/ou consumir seus alimentos e proteger-se do meio ambiente, arcando, total ou parcialmente, com suas despesas de alimentação oumoradia. A independência caracteriza-se quando o local de moradia tem acesso direto, permitindo a seus moradores entrar e sair sem necessidade de passar por locais de moradia de outras pessoas". (Censo Demográfico, 2000). "O domicílio particular é a moradia de uma pessoa ou de um grupo de pessoas, onde o relacionamento é ditado por laços de parentesco, dependência doméstica ou normas de convivência. O domicílio particular é classificado em permanente - localizado em unidade que se destina a servir de moradia (casa, apartamento ou cômodo) e improvisado - localizado em unidade que não tem dependência destinada exclusivamente à moradia (loja, sala comercial, prédio em construção, embarcação, carroça, vagão, tenda, barraca, gruta etc. que esteja servindo de moradia)". O domicílio improvisado, "embora esteja sendo usado para fim residencial, não foi construído para tal fim".
}

Cadernos do Leste 
parte é explicado pela expansão da atividade econômica, do total 5.507 municípios, chegou-se a um total de 1.102 localidade que se constituíram o conjunto dos municípios notáveis. Conjunto esse que abrigava, em 2000, um total aproximado de 34,8 milhões de pessoas e 4,6 milhões de empregos formais, distribuídos, segundo os critérios de hierarquia urbana e localidade geográfica, de forma mais ou menos concentrada nas áreas próximas aos grandes centros econômicos brasileiros.

A fração centro-sul foi claramente a que mais deteve postos de trabalho ocupados, apesar de relativa desconcentração interna. Foi também nessa fração que se verificou asrelações mais favoráveis entre percentuais de emprego formal e população; daí que parteexpressiva do crescimento populacional verificado nos Centros Intermediários e DemaisLocalidades das frações Norte e Nordeste não pôde ser explicado com base no crescimento do emprego formal. As altas taxas de migração verificadas nas diversas localidades da rede contribuíram de forma positiva para o crescimento populacional dessas localidades e estavam vinculadas as oportunidades de emprego experimentadas nessas localidades. E as participações relativas dos imigrantes ocupados nos municípios notáveis mostraram-se mais bem distribuídas do que no conjunto de municípios brasileiros.

No que tange à expansão da pobreza, dada pelo crescimento dos domicíliosimprovisados, verifica-se que ela foi maior entre os notáveis, porém essa expansão foi mais intensa nas áreas de pobreza endêmica da fração norte e em toda fração centro-sul,especialmente nos centros principais. O que sugere que nos centros de maior dinamismo do país é onde se verifica a maior propensão ao surgimento de condições precárias de moradia e com consequente agravamento das condições de vida da população.

De modo geral, as considerações elaboradas ao longo deste estudo indicam que adinâmica do processo de expansão econômica, ocorrida no país durante o último quinquênio da década de 90, consubstanciada pelo aumento do emprego formal, pauta-se pelo comportamento das economias e deseconomias de escala observadas nos grandes centros urbanos brasileiros em detrimento às iniciativas oriundas de outras localidades, muitas vezes à margem de qualquer oportunidade de integração socioeconômica. 


\section{REFERÊNCIAS BIBLIOGRÁFICAS}

DURHAM, E. R. . A caminho da cidade. A vida rural e a migração para São Paulo. 2. ed. São Paulo: Ática, 1973

GERMANI, Gino. Sociologia de lamodernizacion, Buenos Aires, Paidos, 1969. MARTINE, G.; PELIANO, J. Migrante no mercado de trabalho metropolitano. Brasília: Ipea, 1978.

MARTINE, George . Adaptação dos migrantes ou sobrevivência dos mais fortes? . In: HelioMoura. (Org.). Migração Interna: Textos Selecionados. Fortaleza: Banco do Nordeste do Brasil, 1980, p. 949-974.

MATOS, R. E. S. ; FERREIRA, Rodrigo Nunes . Inserção ocupacional de emigrantes das Áreas Metropolitanas de São Paulo e Rio de Janeiro. Revista Brasileira de Estudos da População, Campinas, v. 21, n. 1, p. 83-100, 2004.

OLIVEIRA, O.; STERN, C. Notas sobre a teoria da migração interna: aspectos sociológicos. In: Moura, Helio (Org.). Migração Interna: Textos Selecionados. Fortaleza: Banco do Nordeste do Brasil, 1980, p. 245-265.

RAVESNTEIN, E. G. As leis da migração. In: Helio Moura. (Org.). Migração Interna: Textos Selecionados. Fortaleza: Banco do Nordeste do Brasil, 1980, p. 19-88.

SINGER, Paul. Economia política da urbanização; ensaios. São Paulo: Editora Brasiliense, 1973.

SINGER, Paul. Migrações internas; Considerações teóricas sobre seu estudo In: Economia política da urbanização. São Paulo, Brasiliense, 1976. 